\title{
Complex $360^{\circ}$-reconstruction and stabilization of the cervical spine due to osteomyelitis
}

\author{
Martin Strowitzki • Jan Vastmans • \\ Matthias Vogel $\cdot$ Hans Jaksche
}

Received: 19 August 2010/Revised: 22 October 2010/Accepted: 16 November 2010/Published online: 1 December 2010

(c) Springer-Verlag 2010

\begin{abstract}
Osteomyelitis of the cervical spine may lead to profound bony destruction. The presented case developed multilevel osteomyelitic destruction of the cervical spine after decompression due to cervical myelopathy. He could be cured by a multiple-stage procedure: step one: debridement and removal of all anterior implants with vacuum-assisted closure combined with dorsal instrumentation from $\mathrm{C} 0$ to $\mathrm{T} 3$; step two: anterior reconstruction with expandable titanium cages and plate. The patient regained walking with the aid of a walking frame. The following recommendations are given: multiple stage procedure, extensive debridement and stabilization via an anterior and posterior approach, use of titanium implants.
\end{abstract}

Keywords Vertebral osteomyelitis - Spondylodiscitis . Cervical reconstruction

\section{Introduction}

Osteomyelitis of the cervical spine is a rare event representing $3-6 \%$ of vertebral osteomyelitis $[1,2,25]$. It is mainly caused by haematogenous spread [1, 2, 5, 25, 28], but may also occur as a complication of operative procedures $[1,2,9,25]$. Therapy consists of operative debridement and stabilization either as a single or multiple stage procedure. This is performed via the anterior approach, but

M. Strowitzki $(\bowtie) \cdot$ H. Jaksche

Department of Neurosurgery, Trauma Center Murnau,

Prof.-Küntscher-Str. 8, 82418 Murnau, Germany

e-mail: martin.strowitzki@bgu-murnau.de

J. Vastmans - M. Vogel

Department for Spinal Cord Injuries, Trauma Center Murnau,

82418 Murnau, Germany it is a matter of debate whether anterior or posterior approaches are sufficient or a $360^{\circ}$ stabilization is needed. Combined approaches are advocated in cases with a significant amount of bone destruction [1].

We present a case of postoperative cervical osteomyelitis with multilevel destruction of the cervical spine which could be cured in a multiple stage procedure using a complex reconstruction with posterior $\mathrm{C} 0-\mathrm{T} 3$ fixation and anterior reconstruction using expandable titanium cages and plating.

\section{Case report}

History

The 68-year-old male patient was admitted with progressive tetraparesis due to marked stenosis of the cervical spinal canal from C3 to C6 (Fig. 1). Surgical decompression and fusion $\mathrm{C} 3-\mathrm{C} 6$ via an anterior approach were performed with PEEK-cages and titanium plating (Fig. 2). A first operative revision had to be performed 2 weeks later because of suspected infection. Staphylococcus aureus could be isolated and initially treated with ampicillin/sulbactam and meropenem. Formation of recurrent local abscesses led to five more surgical interventions within the next 12 weeks including evacuation of a mediastinal abscess but finally ended with severe tetraparesis, myelomalacia C3-C6 and diagnosis of epidural abscess C1/C2 (Fig. 3). This was treated by partial resection of the vertebral bodies $\mathrm{C} 3$ and $\mathrm{C} 6$, complete removal of the implanted material, implantation of titanium-cages $\mathrm{C} 2-\mathrm{C} 4$, $\mathrm{C} 4 / \mathrm{C} 5$ and $\mathrm{C} 5-\mathrm{C} 7$ and external stabilization by a halo fixation. Antibiotic therapy was changed to meropenem and linezolid, 1 week later to linezolid, vancomycin and 


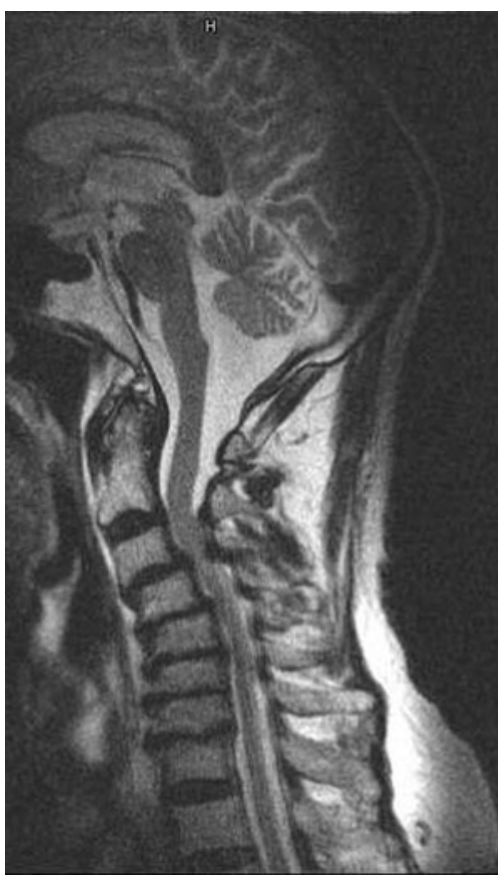

Fig. 1 July 2008: initial MRI depicting marked spinal stenosis C3-C6

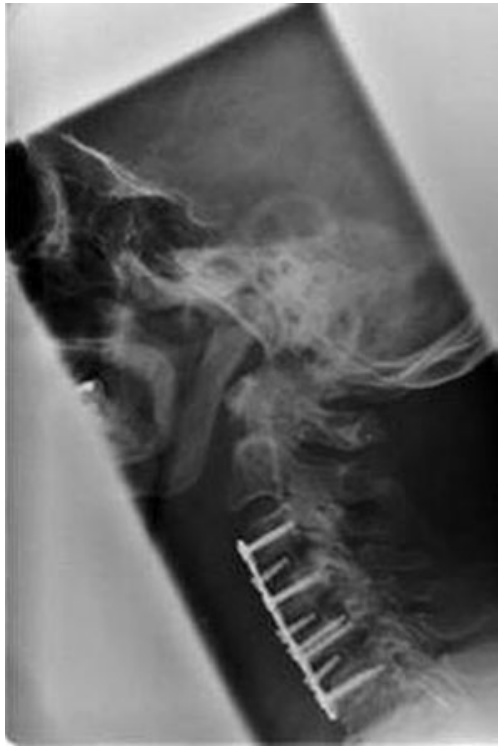

Fig. 2 August 2008: situation after the primary surgical intervention with anterior cage-fusion and plating C3-C6

ceftazidim. Despite these efforts, the patient developed signs of meningitis and pneumonia and was finally transferred to our institution for further treatment.

\section{Examination}

At admission, the patient showed incomplete tetraparesis sub C4, was intubated and artificially ventilated. CT

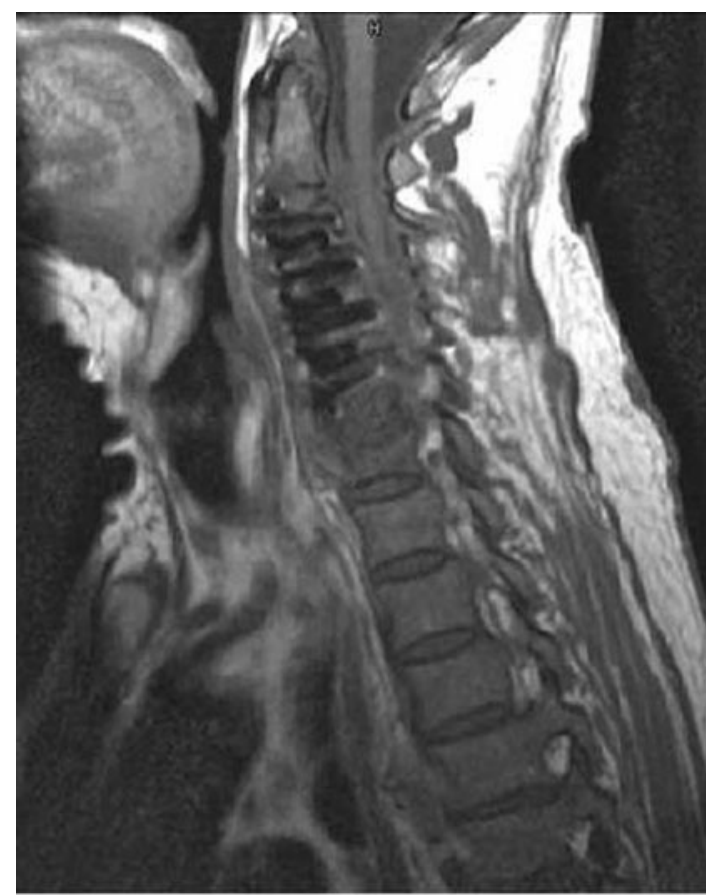

Fig. 3 October 2008: MRI after five local revisions depicting severe osteomyelitis additionally involving the $\mathrm{C} 6 / \mathrm{C} 7$ segment and epidural abscess at the $\mathrm{C} 2$ level

examination showed the anterior screws, plates, and cages removed and replaced by titanium cages bridging the gaps after corpectomy $\mathrm{C} 3$ and partial corpectomy $\mathrm{C} 6$ as well as the disc space $\mathrm{C} 4 / \mathrm{C} 5$. There was additional bony destruction of the non-fused C7/T1 segment and an epidural abscess C1/C2 (Fig. 4a, b).

\section{Therapy}

Antibiotic therapy was changed to clindamycin, fosfomycin and cefotaxim in order to broadly cover the isolated Staphylococcus aureus. On day 3, we performed dorsal stabilization $\mathrm{C} 0-\mathrm{T} 3$ including $\mathrm{C} 1 / \mathrm{C} 2$ fixation according to Magerl and laminectomy $\mathrm{C} 1$. The patient was then turned to a supine position, and the titanium cages were removed via an anterior approach followed by opening of the ventral epidural abscess $\mathrm{C} 1 / \mathrm{C} 2$ via the $\mathrm{C} 2 /$ C3 intervertebral space, application of gentamycin-coated sponges and vacuum-assisted direct skin closure (Fig. 5). Halo fixation was maintained until day 8. At scheduled revision on day 8 , the wound was found without signs of ongoing infection, and final stabilization and closure was planned for day 11 after negative bacterial findings. Ventral stabilization was achieved by implantation of three expandable titanium cages with a diameter of $14 \mathrm{~mm}$, bridging the gap between $\mathrm{C} 2$ and $\mathrm{C} 4$ and between C5 and T1, respectively. A third expandable cage was 

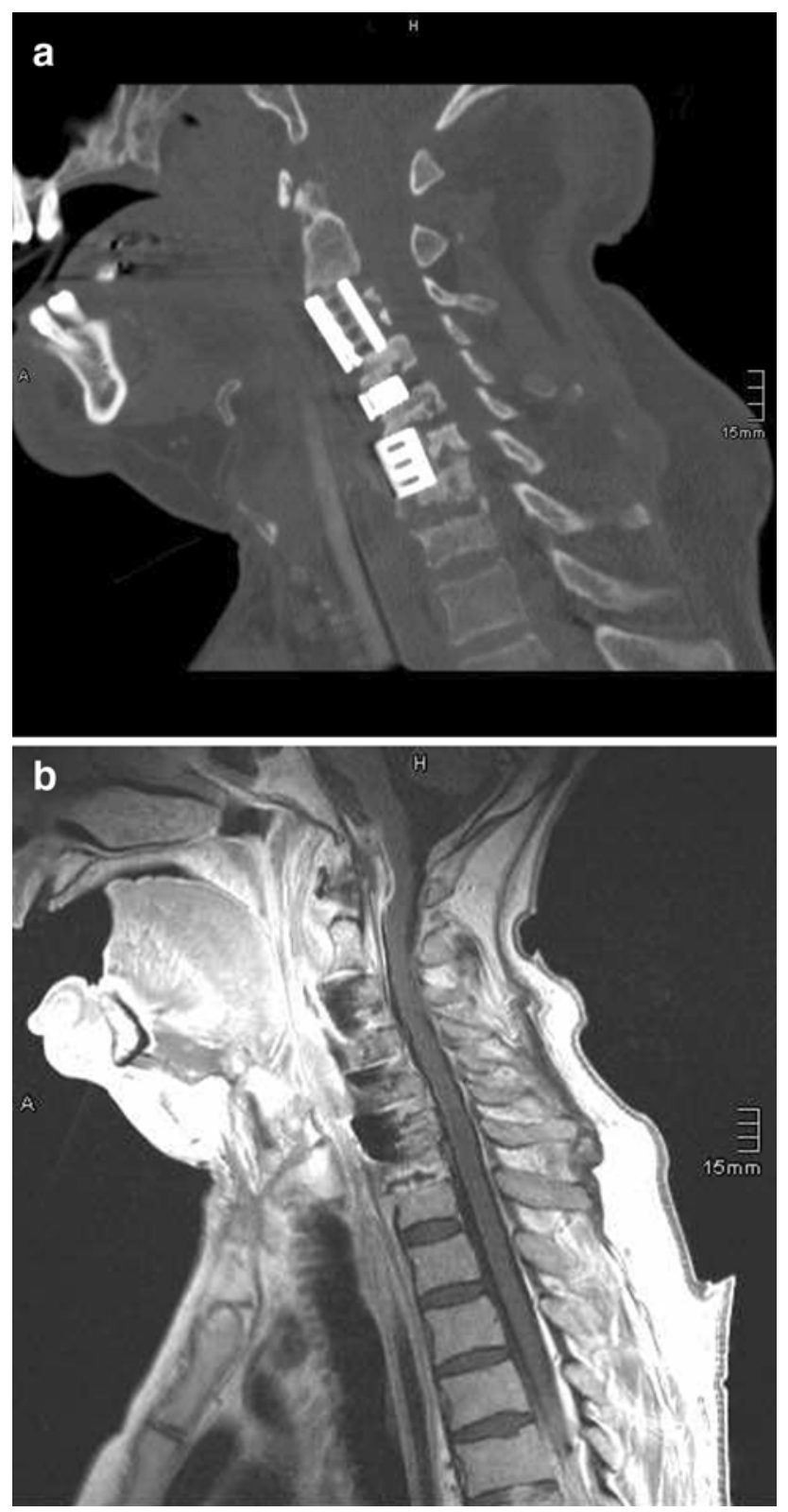

Fig. 4 December 2008: a CT showing the situation on admission at our hospital: screws, plates and cages are removed, titanium cages bridging the gaps after corpectomy $\mathrm{C} 3$ and partial corpectomy $\mathrm{C} 6$ as well as in the disc space C4/C5 are implanted. Note the involvement of the non-fused C7/D1 segment! b Corresponding MRI: note the epidural abscess at the $\mathrm{C} 1-\mathrm{C} 2$ level!

implanted in the C4/C5 intervertebral space (ADD, Ulrich medical, Ulm, Germany). Expandable cages were used because of the rigid posterior stabilization that impeded anterior distraction in order to implant rigid cages. The construct was secured by two trapezoidal Caspar plates (Braun Aesculap, Tuttlingen, Germany), the first covering $\mathrm{C} 4-\mathrm{T} 1$ and the second covering $\mathrm{C} 2-\mathrm{C} 5$ with an overlay of the two plates at the $\mathrm{C} 4$ and $\mathrm{C} 5$ levels (Fig. 6). Tracheotomy was performed on day 32 .

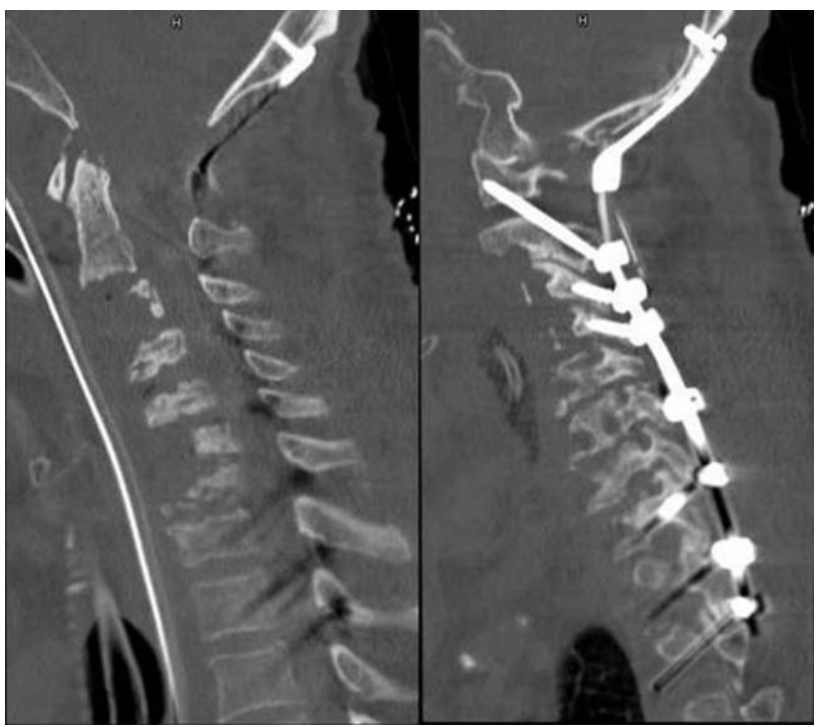

Fig. 5 December 2008: a CT after removal of the anteriorly implanted cages and $\mathbf{b}$ posterior $\mathrm{C} 0-\mathrm{D} 3$ stabilization

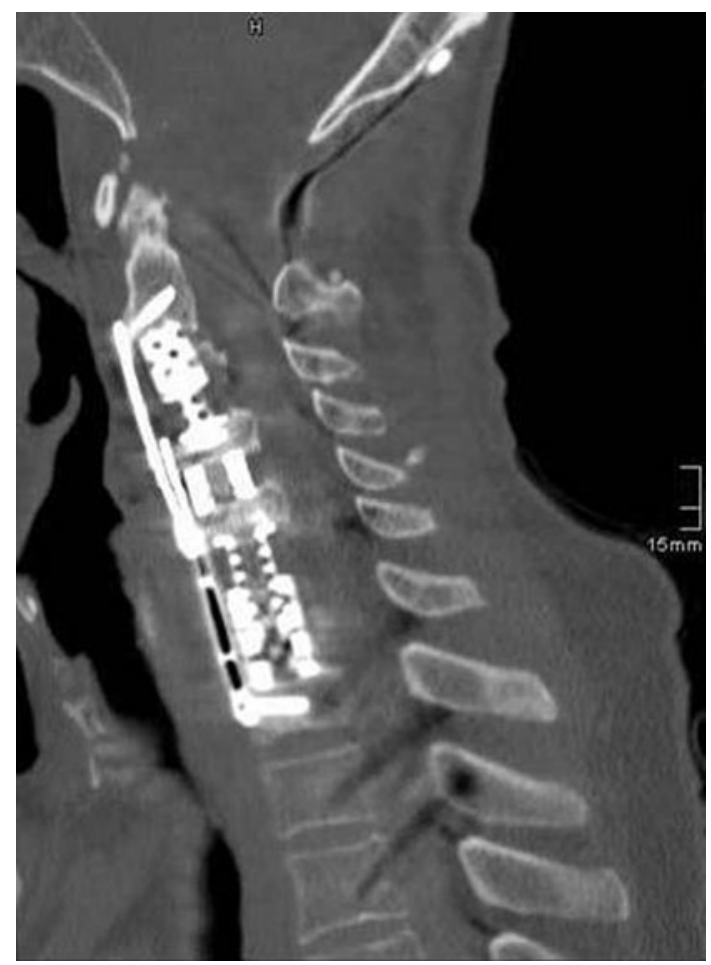

Fig. 6 April 2009: CT depicting final anterior stabilization by three expandable titanium cages bridging the gap $\mathrm{C} 2-\mathrm{C} 4$ and $\mathrm{C} 5-\mathrm{D} 1$ and in the disc space $\mathrm{C} 4 / \mathrm{C} 5$ and Caspar plating $\mathrm{C} 2-\mathrm{D} 1$

\section{Postoperative course}

The patient made a prolonged but continuing neurological recovery within the next 4 weeks and could be transferred to normal ward 7 weeks after admission to our institution with completely healed cervical spine. Antibiotic therapy 


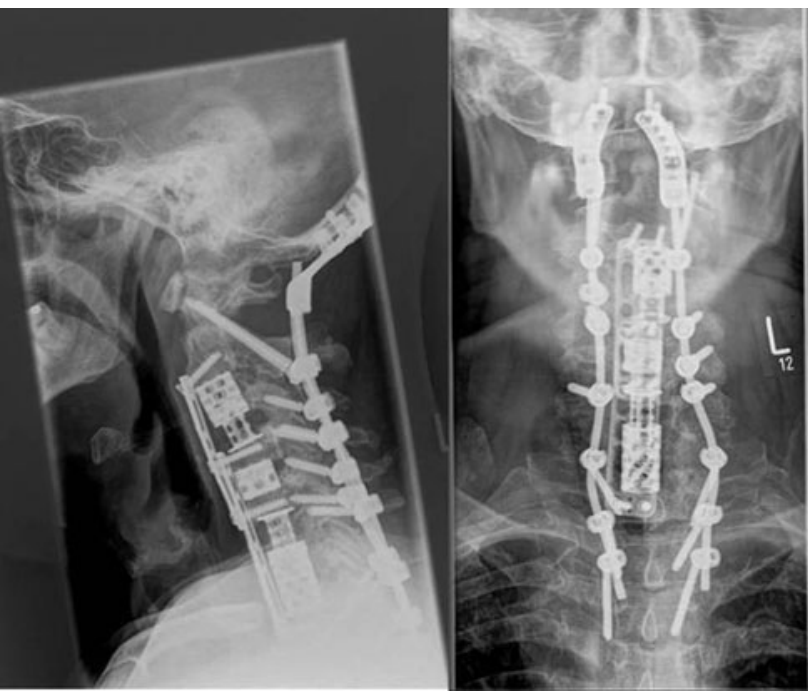

Fig. 7 December 2009: 1-year control depicting stable reconstruction of the cervical spine

could be stopped on day 44. This decision was based on clinical as well as on laboratory criteria. Rehabilitative therapy followed at our institution for three more months. At discharge, the patient still showed residual tetraparesis sub C5 but was able to sit with minor support. Level of strength was 4-5 on the upper as well as on the lower extremities with the exception of the right foot that showed a level 2-3. Swallowing was still severely compromised. Eight months later, the patient lives at home, is able to walk with the aid of a walking frame, and shows slight paresis of right foot extension. There is still dysfunction of the bladder supplied with percutaneous catheter. Implants are stable without dislocation (Fig. 7).

\section{Discussion}

Osteomyelitis of the cervical spine caused by haematogenous spread is a rare event covering about $20 \%$ of spinal osteomyelitis [26]. Cloward reported surgical therapy of two such patients in 1978. He performed anterior debridement and fusion and added posterior wiring and fusion in one patient in a single-stage procedure. Satisfactory results could be achieved [5].

Besides haematogenous spread, postoperative infection after scheduled cervical surgery may lead to severe osteomyelitis with formation of epidural abscesses and bony destruction [25].

Independently of its origin, cervical osteomyelitis requires surgical intervention in the presence of a neurologic deficit, extensive bony destruction, paravertebral or epidural abscess formation and persistent septicaemia $[1,2$, $12,25]$. Anterior debridement and spondylodesis seem to be sufficient in cases without instability and severe deformity [6, 10, 13], but multisegmental involvement or distinct substance loss requires a combined anterior-posterior approach [10, 13, 23, 24]. Most of these reports deal with the thoracic and lumbar spine, but results may be transferred to the cervical spine too $[1,2,10,24]$.

Some controversy exists whether anterior and posterior approaches should be performed as single or even multiple stage procedures $[8,11,18,20,21,27]$. Isenberg et al. report their experience in 34 patients with reduced general condition. One of these patients had involvement of the cervical spine, but unfortunately his case is not reported in detail. Altogether, the authors advocate a multiple stage procedure. Patients with monosegmentary involvement had ventral debridement as step 1 and ventral fusion/stabilization as step 2. Patients with multisegmentary involvement had ventral debridement and posterior decompression as step 1 and ventral fusion/stabilization as the final step [11].

Titanium mesh cages as well as titanium expandable cages do not increase the rate of recurrence or persistence of infection and thus can be used for stabilising the infected spine. This is true for the thoraco-lumbar region $[7,14,16$, $18,19,24]$, as well as for the cervical spine [15-17, 24]. Furthermore, a direct comparison between autologous iliac bone strut and cages did not show a difference in clinical and imaging outcomes [22]. Safe use of expandable titanium cages has been demonstrated for the thoraco-lumbar region $[18,19]$, but has not been reported yet in detail for the cervical spondylitic spine. Figures depicting the use of expandable cages in cervical vertebral body replacement are given in the papers published by Lee [17] and Acosta [1] in 2004 without going into details.

Our patient was transferred in a reduced general condition with ongoing destructive multisegmentary cervical osteomyelitis despite multiple surgical interventions. At admission to our hospital, there was partial resection of the C3 and C6 vertebral bodies, and titanium cages were implanted as substitute of these two vertebral bodies and in the intervertebral space $C 4 / 5$. In accordance with Isenberg et al. [11], we decided in favour of a multiple stage procedure. Step 1 consisted of dorsal stabilization $\mathrm{C} 0-\mathrm{T} 3$ with bony decompression at the C1-level and removal of the implanted titanium cages. The anterior approach was closed with vacuum assistance, and final anterior stabilization could be achieved after one scheduled revision of the VAC system on day 11. Because of the rigid posterior stabilization, we used expandable cages that are reported not to disturb the healing process in the spondylitic thoraco-lumbar spine $[18,19]$ and the well-established Caspar plating with titanium plates and screws [3,4]. This led to safe and stable reconstruction and marked neurological amelioration. It has to be reemphasized that we did not use bone graft for anterior as well as for posterior fusion due to 
the severe infectious state at the beginning. This might be debatable, but we relied on instrumentation alone and did not observe any implant failure up to now.

This case demonstrates that even the severely destroyed cervical spine can be cured with the following recommendations: multiple stage procedure, extensive debridement and stabilization via an anterior and posterior approach, use of titanium implants. Systemic as well as local antibiotics shall be used, and in cases with purulent tissue, vacuum-assisted closure is advocated.

Conflict of interest None of the authors has any potential conflict of interest.

\section{References}

1. Acosta F Jr, Chin C, Quinones-Hinojosa A, Ames C, Weinstein P, Chou D (2004) Diagnosis and management of adult pyogenic osteomyelitis of the cervical spine. Neurosurg Focus 17:E2

2. Barnes B, Alexander J, Branch C Jr (2004) Cervical osteomyelitis: a brief review. Neurosurg Focus 17:E11

3. Bose B (1998) Anterior cervical fusion using Caspar plating: analysis of results and review of the literature. Surg Neurol 49:25-31

4. Caspar W, Barbier DD, Klara PM (1989) Anterior cervical fusion and Caspar plate stabilization for cervical trauma. Neurosurgery 25:491-502

5. Cloward RB (1978) Metastatic disc infection and osteomyelitis of the cervical spine. Surgical treatment. Spine 3:194-201

6. Eysel P, Hopf C, Vogel I, Rompe JD (1997) Primary stable anterior instrumentation or dorsoventral spondylodesis in spondylodiscitis? Results of a comparative study. Eur Spine J 6:152-157

7. Fayazi AH, Ludwig SC, Dabbah M, Bryan Butler R, Gelb DE (2004) Preliminary results of staged anterior debridement and reconstruction using titanium mesh cages in the treatment of thoracolumbar vertebral osteomyelitis. Spine J 4:388-395

8. Frangen TM, Kälicke T, Gottwald M, Andereya S, Andress HJ, Russe OJ et al (2006) Surgical management of spondylodiscitis. An analysis of 78 cases. Unfallchirurg 109:743-753 (in German)

9. Ghanayem AJ, Zdeblick TA (1996) Cervical spine infections. Orthop Clin North Am 27:53-67

10. Heyde C, Boehm H, El Saghir H, Tschöke S, Kayser R (2006) Surgical treatment of spondylodiscitis in the cervical spine: a minimum 2-year follow-up. Eur Spine J 15:1380-1387

11. Isenberg J, Jubel A, Hahn U, Seifert H, Prokop A (2005) Multistep spondylosyndesis-surgical management of progressive spondylodiscitis in patients with critical physical status. Orthopade 34:159-166 in German
12. Jeanneret B, Magerl F (1994) Treatment of osteomyelitis of the spine using percutaneous suction/irrigation and percutaneous external spinal fixation. J Spinal Disord 7:185-205

13. Klöckner C, Valencia R, Weber U (2001) Sagittal alignment following surgical therapy of destructive spondylodiscitis: ventral or ventrodorsal procedure-a comparison of results. Orthopade 30:965-976

14. Korovessis P, Petsinis G, Koureas G, Iliopoulos P, Zacharatos S (2006) Anterior surgery with insertion of titanium mesh cage and posterior instrumented fusion performed sequentially on the same day under one anaesthesia for septic spondylitis of thoracolumbar spine: is the use of titanium mesh cage safe? Spine 31:1014-1019

15. Korovessis P, Petsinis G, Koureas G, Iliopoulos P, Zacharatos Z (2006) One-stage combined surgery with mesh cages for treatment of septic spondylitis. Clin Orthop Relat Res 444:51-59

16. Korovessis P, Repantis T, Iliopoulos P, Hadjipavlou A (2008) Beneficial influence of titanium mesh cage on infection healing and spinal reconstruction in hematogenous septic spondylitis. Spine 33:759-767

17. Lee M, Wang M, Fessler R, Liauw J, Kim D (2004) Instrumentation in patients with spinal infection. Neurosurg Focus 17:E7

18. Lerner T, Hackenberg L, Rösler S, Joosten U, Halm H, Liljenqvist U (2005) Surgical therapy of unspecific and specific spondylodiscitis. Z Orthop Ihre Grenzgeb 143:204-212 in German

19. Liljenqvist U, Lerner T, Bullmann V, Hackenberg L, Halm H, Winkelmann W (2003) Titanium cages in the surgical treatment of severe vertebral osteomyelitis. Eur Spine J 12:606-612

20. Linhardt O, Krüger A, Krödel A (2004) First results of anterior versus posterior instrumentation-fusion in the treatment of spondylodiscitis. Z Orthop Ihre Grenzgeb 142:73-78 (in German)

21. Ogden A, Kaiser M (2004) Single-stage debridement and instrumentation for pyogenic spinal infections. Neurosurg Focus 17:E5

22. Pee YH, Park JD, Choi YG, Lee SH (2008) Anterior debridement and fusion followed by posterior pedicle screw fixation in pyogenic spondylodiscitis: autologous iliac bone strut versus cage. J Neurosurg Spine 8:405-412

23. Przybylsky GJ, Sharan AD (2001) Single stage autogenous bone grafting and internal fixation in the surgical management of pyogenic discitis and vertebral osteomyelitis. J Neurosurg 94:1-7

24. Ruf M, Stoltze D, Merk H, Ames M, Harms J (2007) Treatment of vertebral osteomyelitis by radical debridement and stabilization using titanium mesh cages. Spine 32:275-280

25. Schimmer R, Jeanneret C, Nunley P, Jeanneret B (2002) Osteomyelitis of the cervical spine: a potentially dramatic disease. J Spinal Disord Tech 15:110-117

26. Schinkel C, Gottwald M, Andress HJ (2003) Surgical treatment of spondylodiscitis. Surg Infect 4:387-391

27. Suess O, Weise L, Brock M, Kombos T (2007) Debridement and spinal instrumentation as a single-stage procedure in bacterial spondylitis/spondylodiscitis. Zentralbl Neurochir 68:123-132

28. Yang EC, Neuwirth MG (1988) Pseudomonas aeruginosa as a causative agent of cervical osteomyelitis. Case report and review of the literature. Clin Orthop Relat Res 231:229-233 